\title{
Quercetin and cancer: new insights into its therapeutic effects on ovarian cancer cells
}

\author{
Asma Vafadar ${ }^{1 \dagger}$, Zahra Shabaninejad ${ }^{2,3+}$, Ahmad Movahedpour ${ }^{1,4}$, Farzaneh Fallahi ${ }^{5}$, Mona Taghavipour 6 , \\ Younes Ghasemi ${ }^{1,3,7}$, Maryam Akbari ${ }^{8}$, Alimohammad Shafiee ${ }^{9}$, Sarah Hajighadimi ${ }^{9}$, Sanaz Moradizarmehri ${ }^{9}$, \\ Ebrahim Razi ${ }^{10^{*}}$, Amir Savardashtaki ${ }^{1,3^{*}}$ and Hamed Mirzaei ${ }^{5^{*}}$
}

\begin{abstract}
Ovarian cancer is known as a serious malignancy that affects women's reproductive tract and can considerably threat their health. A wide range of molecular mechanisms and genetic modifications have been involved in ovarian cancer pathogenesis making it difficult to develop effective therapeutic platforms. Hence, discovery and developing new therapeutic approaches are required. Medicinal plants, as a new source of drugs, could potentially be used alone or in combination with other medicines in the treatment of various cancers such as ovarian cancer. Among various natural compounds, quercetin has shown great anti-cancer and anti-inflammatory properties. In vitro and in vivo experiments have revealed that quercetin possesses a cytotoxic impact on ovarian cancer cells. Despite obtaining good results both in vitro and in vivo, few clinical studies have assessed the anti-cancer effects of quercetin particularly in the ovarian cancer. Therefore, it seems that further clinical studies may introduce quercetin as therapeutic agent alone or in combination with other chemotherapy drugs to the clinical setting. Here, we not only summarize the anti-cancer effects of quercetin but also highlight the therapeutic effects of quercetin in the ovarian cancer.
\end{abstract}

Keywords: Quercetin, Ovarian cancer, Therapy

\section{Introduction}

According to a 2018 report, ovarian cancer ranked as the seventh most prevalent female cancer across the world, with approximately 240,000 new subjects [1]. Ovarian cancer usually is diagnosed in advanced stages, since it is associated with silent and unclear symptoms [2]. Despite extensive knowledge obtained on this complication in recent years, the rate of survival has not improved

\footnotetext{
*Correspondence: ebirazi2015@gmail.com; Dashtaki63@gmail.com; h.mirzaei2002@gmail.com; Mirzaei-h@kaums.ac.ir

${ }^{\dagger}$ Asma Vafadar and Zahra Shabaninejad contributed equally to this work ${ }^{1}$ Department of Medical Biotechnology, School of Advanced Medical Sciences and Technologies, Shiraz University of Medical Sciences, Shiraz, Iran

${ }^{5}$ Research Center for Biochemistry and Nutrition in Metabolic Diseases, Institute for Basic Sciences, Kashan University of Medical Sciences, Kashan, I.R. of Iran

${ }^{10}$ The Advocate Center for Clinical Research, Ayatollah Yasrebi Hospital, Kashan, Iran

Full list of author information is available at the end of the article
}

significantly because of some challenges in diagnosing and treatment it as early as possible [3]. Different modifications in molecular and genetic levels in ovarian cancer result in some challenges to establish a therapeutic platform [4].

According to a wide range of experiments, phytochemicals including polyphenols, flavones, as well as flavonoids possess considerable anti-cancer features, which can be employed against different kinds of cancers [5]. In this regard, quercetin, which can be extensively observed in daily foods including nuts, teas, vegetables, different plants, and in general the daily dietary program of people, is a common phytochemical [6]. Moreover, this supplementary agent is commercially accessible, while its oral application at a dose of $1 \mathrm{~g}$ per day is safe enough and can be absorbed up to $60 \%$ [7]. An extensive range of pharmacologic activities has been reported for quercetin, including anti-oxidant, anti-diabetes, anti-inflammation, as well as anti-proliferation [8, 9]. Quercetin, 
2-(3,4-dihy-droxyphenyl)-3,5,7-trihydroxy4H-chromen4-one includes two benzene rings named $\mathrm{A}$ and $\mathrm{B}$, and joined through a 3-carbone heterocyclic pyrone one [9]. Since two antioxidant pharmacophores are present in the structure of quercetin, it can largely remove free radicals and join to transitional metal ions [9]. Moreover, catechol along with the $\mathrm{OH}$ group presenting at the position C3 in the structure of quercetin is an ideal arrangement to scavenge free radicals [9]. This agent is a pentalhydroxyl-flavonol consisting of 5 hydroxyl groups on the flavonol structure at 3, 30, 405 , and 7 position carbons. Replacement of various functional groups leads to different biochemical as well as pharmacologic properties of quercetin [10].

Some studies have indicated that quercetin may exist in two states: (i) free or aglycone and (ii) mixed with different molecules. It can be interacted with molecules including, carbohydrates, lipids, alcohols, as well as sulfate group to generate derivatives of quercetin such as quercetin glycoside, prenylated quercetin, quercetin ethers and quercetin sulfate [10].

Furthermore, significant number of studies focused on anti-cancer properties of this bioactive compound. Several pathways have been identified which are affected by quercetin in different cancers $[11,12]$. Based on available evidences, quercetin can inhibit a broad range of cancers such as breast [13], lung [14], nasopharyngeal [15], kidney [16], colorectal [17], prostate [18], pancreatic [19], as well as ovarian [20] cancers. According to the previous literature, consuming vegetables that are rich in quercetin has been associated with lower risks of ovarian cancer [21]. Similarly, consuming fruits with high levels of quercetin, including apples as well as citrus or their juice can decrease occurrence of ovarian cancer [22].

Quercetin is not harmful for healthy cells, while it can impose cytotoxic effects on cancer cells through several mechanisms, making it a good candidate to treat ovarian cancer or to be employed as a supplementary factor along with other anti-cancer medications [23]. In this review, we summarized the recent and eminent researches on quercetin properties in cancer therapy, especially ovarian cancer.

\section{Quercetin and its biologic functions}

Quercetin is an ordinary flavonoid that is pervasive in various types of foods and plant. Quercetin glycosides are the dominant flavonoid content that can be found in propolis along with other healthy foods, including fruits and vegetables; particularly onion, broccoli, apple, tea, as well as red wine. International Union of Pure and Applied Chemistry (IUPAC) has called it 3,3',4',5,7-pentahydroxyflavone (Fig. 1). Another name for this agent is

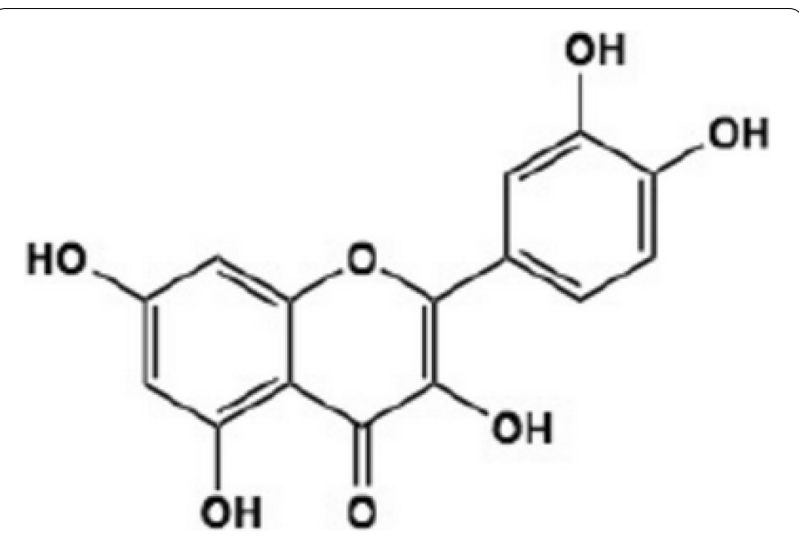

Fig. 1 Chemical structure of quercetin (Q1)

3,3', 4',5,7-pentahydroxy-2-phenylchromen-4-one, and five hydroxyl groups are present at the positions 3,5 , $7,3^{\prime}$ and $4^{\prime}$ of the flavonoid as its typical characteristic [24-26]. Quercetin can be used as a nutritional supplement. Quercetin is reported to have several beneficial effects on human health such as anti-inflammatory effects, cardiovascular protection and anticancer activity. It can act as an anti-cancer, anti-tumor, anti-ulcer, anti-allergy, anti-viral, anti-inflammation, and antidiabetes agent, exerting gastro-protection, anti-hypertension, immune-modulation, as well as anti-infection features are among its advantageous effects [27].

Ferry and colleagues have investigated the pharmacokinetic effects of intravenously injected quercetin in the patients with cancer at doses of $60-2000 \mathrm{mg} /$ $\mathrm{m}^{2}$. The safe dose of $945 \mathrm{mg} / \mathrm{m}^{2}$ was identified by the researchers. At higher doses that were toxic, vomiting, high blood pressure, nephrotoxicity, as well as decreased serum potassium could be observed. The dispensation and removal half-life of quercetin applied intravenously, is $0.7-7.8 \mathrm{~min}$, and $3.8-86 \mathrm{~min}$, correspondingly. Elimination is $0.84 \mathrm{~L} / \mathrm{min} / \mathrm{m}^{2}$, and dispensation content is $3.7 \mathrm{~L} / \mathrm{m}^{2}$ [28]. Pharmacokinetic characteristics of oral administration of 8,20 , and $500 \mathrm{mg}$ quercetin aglycone were examined in healthy volunteers by Erlund et al. [29]. On the other hand, Graefe and colleagues examined the pharmacokinetic features of this agent at a dose of $200 \mathrm{mg}$. $C_{\max }$ as well as $\mathrm{T}_{\max }$ of quercetin have been reported to be $2.3 \pm 1.5 \mu \mathrm{g} / \mathrm{mL}$ and $0.7 \pm 0.3 \mathrm{~h}$, correspondingly [30].

Angiogenesis is one of very important cancer-related processes. It has been showed, quercetin exerts its antiangiogenesis effects in various cancers (Fig. 2) [31]. Moreover, quercetin is capable to protect against free radicals including smoking. Free radicals originated from cigarette tar can impose irreparable damages to erythrocyte membranes. In addition, quercetin and its 


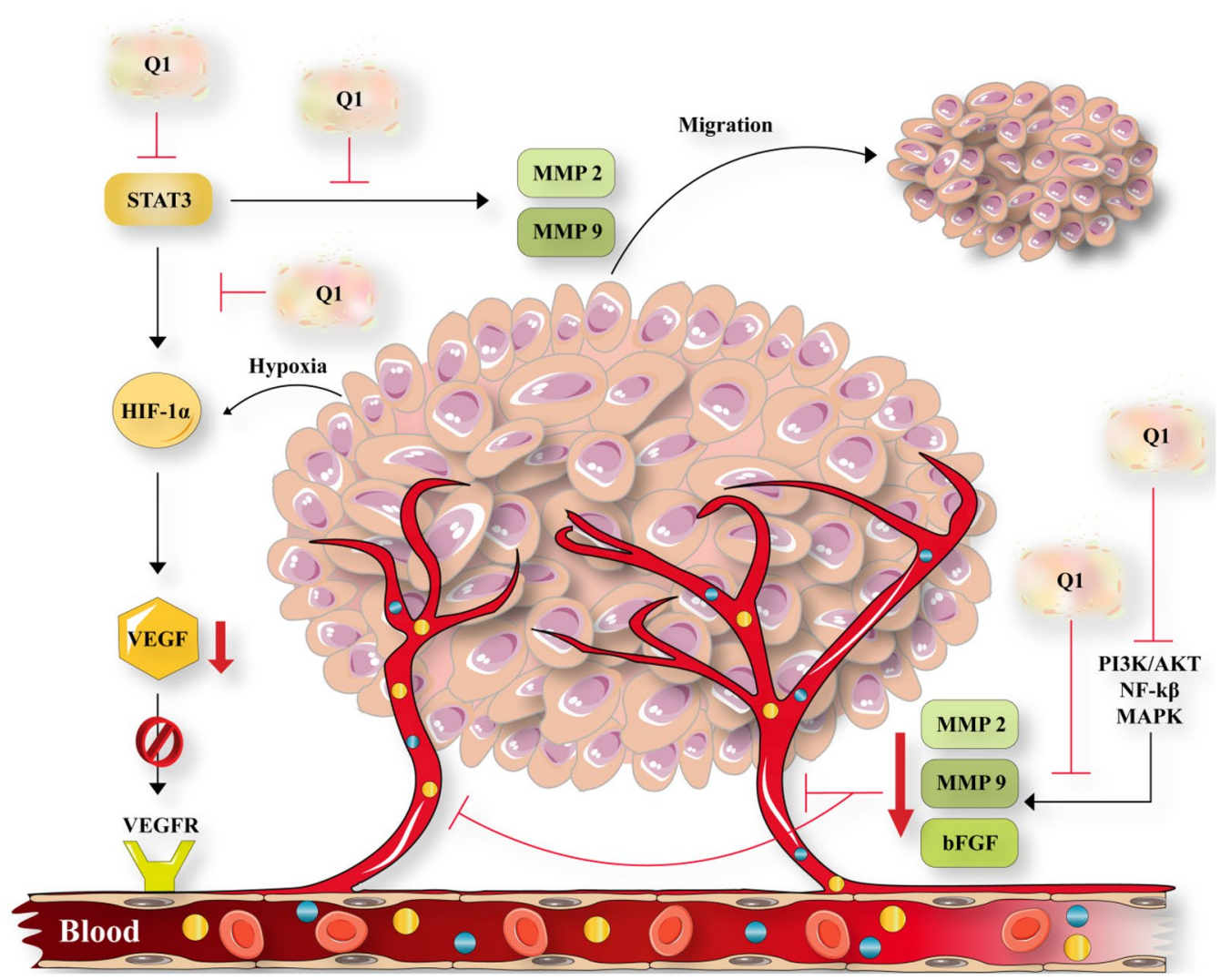

Fig. 2 Anti-angiogenesis effects of quercetin

conjugate metabolites have been reported to possess the potential to protect erythrocytes against damage of the membrane resulted from smoking [32].

Inflammation, through which self-protecting measures are taken, is a type of biologic reaction in the case human body experiences damaging or troublesome stimuli. The aim of this process is removing of the injured cells, pathogens, or other adverse stimuli, while beginning the treatment procedure. Inflammatory conditions are not essentially equal to infection. Infection is usually resulted from a viral, bacterial, or fungal source, but inflammatory processes include the reaction of the human body toward healing itself $[33,34]$. The potential of quercetin in modulation of inflammation is one of its critical and considerable features. Accordingly, inflammatory enzymes of cyclooxygenase (COX) and lipoxygenase are inhibited by this agent and consequently inflammatory mediators including prostaglandins as well as leukotrienes are reduced [33, 34].

Nutritionists at Michigan State University studied the general effects of dietary flavonoids including quercetin as systemic anti-inflammation elements [35]. Increased level of $C$-reactive protein (CRP) was related to several disease conditions consisting of being obese, experiencing heart problems, as well as lupus. The researchers concluded that consumption of specific foods lowers the levels of inflammation risk factors (CRP).

Pre-clinical investigations have shown that quercetin can significantly reduce the levels of inflammation moderators including NO synthase, COX-2, as well as CRP in human hepatocyte-derived cell line [36]. Regarding experiments carried out on rats, quercetin $(80 \mathrm{mg}$ equivalent dose) hindered acute and chronic inflammatory conditions, while it also indicated considerable antiarthritic properties against adjuvant-induced arthritis $[37,38]$.

In a study performed by Askari and colleagues, the impact of 2-month flavonoid quercetin (500 mg) supplement was examined in healthy amateur sportsmen having regular exercise. The results of this study indicated a considerable reduction in CRP levels [39]. Nevertheless, in pathologic conditions, this agent did not cause considerable changes in CRP levels in women who had rheumatoid arthritis (RA). The study continued in an 8-week interval, and the RA patients received $500 \mathrm{mg}$ /day of quercetin [40]. Moreover, quercetin hampers the accumulation of uric acid due to its capability of inhibiting 
xanthine oxidase, which is probably beneficial in patients suffering gout [41].

Quercetin has also antibacterial potential regarding approximately all kinds of bacteria, and especially influences gastrointestinal, respiratory, urinary, as well as dermal systems. Its anti-infection and anti-replication properties are probably due to its antiviral features. Viruses that usually react to flavonoids include adenovirus, herpes simplex virus, Japanese encephalitis virus, as well as respiratory syncytial virus $[42,43]$.

Quercetin possesses anti-allergic properties through inhibition of releasing histamine from mast cells along with other allergic substances; therefore, it plays the role of a natural antihistamine. The potential of quercetin in prevention of allergies results in significant implications to employ it to treat and prevent asthma and bronchitis. The cell membranes of mast cells have the role of an immune gateway for the brain, the environment, as well as emotional stress [44].

Although a broad range of biologic advantages was mentioned above, quercetin pharmaceutical application and clinical conditions have been constrained due to its low hydro-solubility, lack of stability in physiologic conditions along with low bioavailability. [45]. It is worth considering that the anticancer properties of quercetin may be dependent to some extent on its metabolites [4648]. Currently, several analogs having better solubility and possessing various biologic features such as biphasic, inotropic and lusitropic impacts have been introduced $[49,50]$.

A review described the anticancer properties of a small collection of quercetin analogs, while the hydrophilicfree $\mathrm{OH}$ have been completely or partially covered with groups that are conveniently removed considering in vivo conditions. Particularly, hydroxyl groups of the natural compound were replaced with different combinations, including acetyl esters, ethyl or benzyl ethers, or diphenyl ketal of the catechol system. Alterations made in the chemicals resulted in compounds that had better anti-cancer properties regarding quercetin. In addition, the potential of the proposed analogs in inhibition of human topoisomerases I and II was examined through direct enzymatic assays along with docking analyses [51]. Eventually, findings regarding the capability of lead compounds in modulation of intracellular ROS generations could be recorded.

\section{The effect of quercetin on cancers}

Despite many advances in treating cancer, it is still known as a life-threatening malignancy in human. Although chemotherapy is employed as the conventional treatment for cancer, it has been illustrated that its usage is restricted in most cancers because of reasons including chemotherapy resistance and side effects.

Nowadays, natural compounds such as quercetin have been recognized as significant agent for preventing and healing cancer because of their predictable performance, high therapeutic potential and their low toxicity. It seems that quercetin plays an important role as an anti-proliferative and anticancer agent and also stimulates apoptosis (Fig. 3) [52]. Numerous studies probed the influence of isolated quercetin compound in different cancer cell lines. Obviously, quercetin has repressed the proliferation of cancers such as gastric cancer (GC) [53], breast cancer [54], colorectal cancer (CRC) [55], oral cancer [56], liver cancer [57], prostate cancer [58], thyroid cancer [59], leukemia [60], pancreatic cancer [61] and lung cancer [62].

\section{Quercetin and gastrointestinal cancers}

Gastrointestinal cancers, the leading causes of cancerrelated mortality worldwide, account for one fourth of all malignancies and for $9 \%$ of all cancer deaths [63], have elevating rate of incidence and heavy health burden on society [64]. Quercetin significantly suppressed $\mathrm{GC}$ cell viability, migration and invasion activities via decreasing expression of urokinase plasminogen activator ( $\mathrm{uPA}$ ) and $\mathrm{uPA}$ receptor (uPAR) proteins, which are strongly associated with GC metastasis. Quercetin could be used as an anti-metastatic agent against GC metastasis cells through interfering with uPA/uPAR systems, AMPK $\alpha$, NF- $\kappa \beta$, ERK $1 / 2$, and PKC- $\delta$ regulation [65]. Recently, quercetin was carried with a novel phenyl boronic acid (PBA) conjugated $\mathrm{ZnO}$ nanoparticles (PBA-ZnO-Q) construct. It was determined that PBA$\mathrm{ZnO}-\mathrm{Q}$ can be efficient in diminishing tumor growth, in vivo. KRAS is a mutant oncogenic gene in up to $40 \%$ of CRC patient that has been confirmed leads to resistant chemotherapy and poor prognosis in CRC cases [17, $66,67]$. Investigation of quercetin effects on CRC cells carrying KRAS mutant gene revealed that quercetin could decrease the cell viability and increase apoptosis in cancer cells based on MTT assay and colony formation methods. The possible underlying mechanisms are the AKT pathway repression and activation of the c-Jun $\mathrm{N}$-terminal kinase (JNK) pathway in KRAS-mutant cells. [17]. Gold nanoparticles (AuNPs)-quercetin into poly DLlactide-co-glycolide nanoparticles significantly repressed the cell proliferation, colony formation, progression and cell migration of liver cancer. According to data, this construct containing quercetin increased the apoptosis via enhancing of caspase-3, caspase-9, and provoked more freeing of cytochrome c (cyto-c). Quercetin nanoparticle also repressed Akt/ERK1/2 signaling pathway, telomerase reverse transcriptase (hTERT) via impending $\mathrm{AP}-2 \beta / \mathrm{hTERT}$, and cyclooxygenase $2(\mathrm{COX}-2)$ through 


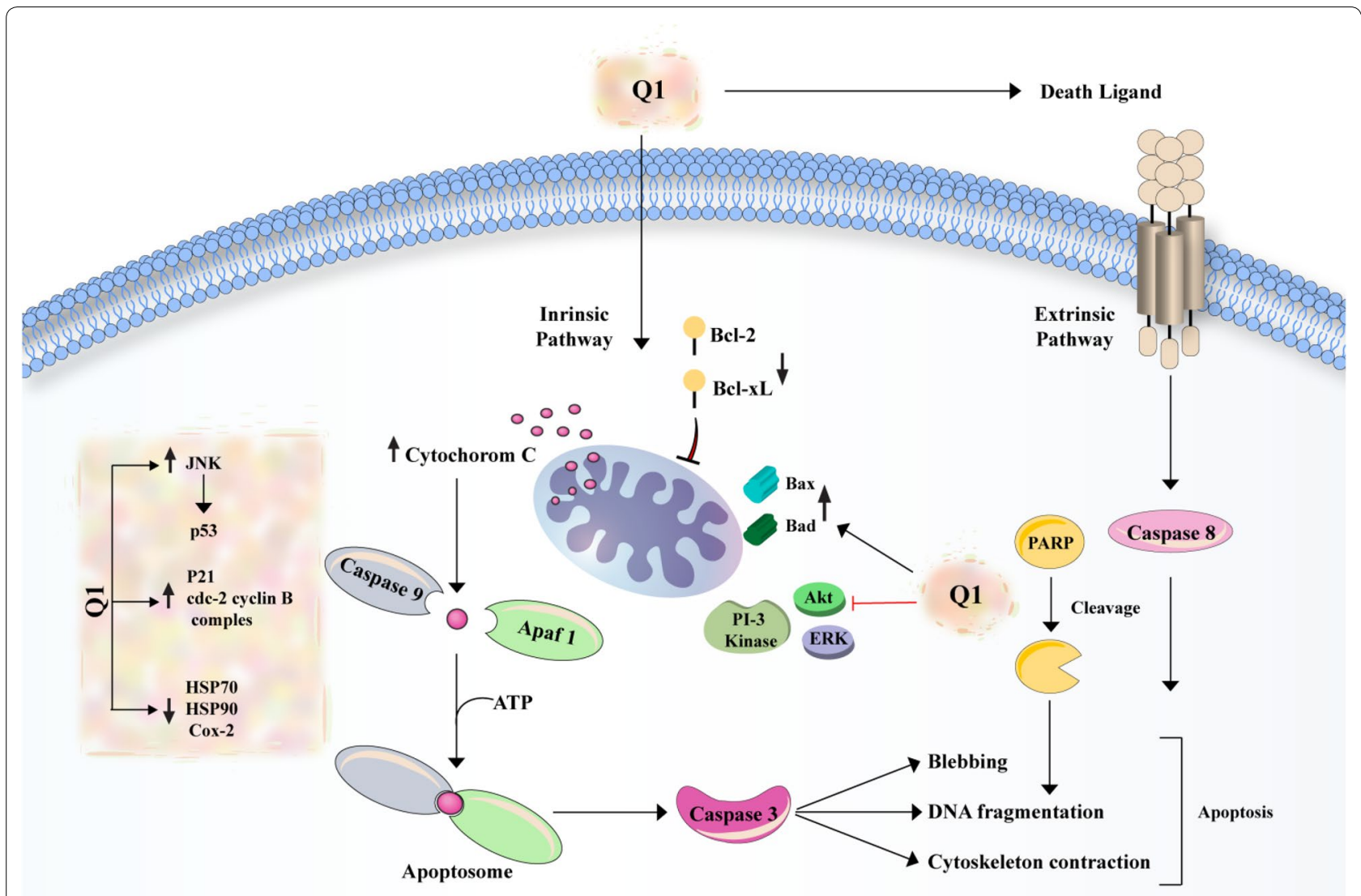

Fig. 3 A schema of the effects of quercetin on apoptosis

inactivated the NF- $\mathrm{kB} / \mathrm{COX}-2$. [68]. Treating HSC-6 and SCC-9 cell lies, oral cancer originated cell lines, with $50 \mu \mathrm{M}$ of quercetin showed inhibited cell viability, migration, and invasion via attenuated the excesses of MMP-9 and MMP-2 in those cells. Beside, quercetin treatment alleviated the miR-16 expression, which were upregulated in oral cancer cell line and tissues.

\section{Quercetin and hematological cancers}

Hematological cancers are diseases of abnormal progenitor and stem cells, originating from epigenetic and genetic alterations that lead to the dysregulation of differentiation, proliferation, and self-renewal of cells [69]. In the majority of these malignancies, the bone marrow, along with peripheral blood, lymphatic nodes, and spleen, as secondary lymphoid organs, are main locations for tumour localisation [70]. Quercetin has been also proved to possess beneficial effects on hematological cancers. He and his co-workers carried out an investigation and showed that quercetin inhibits proliferation of MM.1R, ARP-1, and RPMI8226 multiple myeloma cell lines through inducing apoptosis as well as cell cycle arrest in the G2/M phase. Moreover, the combination of quercetin with dexamethasone further enhanced apoptosis and inhibited tumor growth [71]. In another study, $\mathrm{Ma}$ et al. reported that quercetin inhibits multiple myeloma cells proliferation via down-regulating the expression of IQGAP1 and ERK activation [72]. It has been indicated that quercetin suppresses STAT3 and PI3K/ $\mathrm{AKT} / \mathrm{mTOR}$ pathways in primary effusion lymphoma (PEL) cells leading to downregulate the prosurvival cellular proteins expression, including cMyc, cyclin D1, and c-FLIP. Furthermore, quercetin decreased the IL-6 and IL-10 release, resulting in PEL cell death. A prosurvival autophagy was also mediated by quercetin, which promoted the cytotoxic effects of bortezomib, a proteasomal inhibitor [73]. Ha and colleagues demonstrated that quercetin induced cytoprotective autophagy and intrinsic apoptosis, and the suppression of autophagy with chloroquine potentiates apoptotic ability of quercetin in human $\mathrm{T}$ cell acute lymphoblastic leukemia Jurkat clones [74]. According to former studies, it was clarified TNF-related 
apoptosis-inducing ligand (TRAIL) as a biological cytokine playing important role in promoting apoptosis through attaching to its agonist receptors in cancer cells but its utilization has been limited because of resistance to some cancers [75, 76]. For this reason, a group of scientists has explored the synergist effect of quercetin and TRAIL in human myeloid leukemia KG-1 cells and showed that quercetin can be employed as a sensitizing factor alongside with TRAIL promoted the influence of TRAIL-induced apoptosis in KG-1 cells. On the basis of quantitative Real-time PCR results, it was observed the expression level of death receptor (DR) genes including DR4 and DR5 after treating with quercetin were increased and also the p65 expression and antiapoptotic proteins including c-IAP1, c-IAP2, and XIAP were reduced [75].

\section{Quercetin and gynecological cancers}

Gynecologic malignancies are the fourth most prevalent type of cancers in females and influence the organs and tissue of the reproductive system of women, such as the vulva-vagina, cervix, uterus, and ovaries [77-79]. To prove the effectiveness of quercetin for the treatment of gynecological malignancies, numerous researches have been performed. For example, Lin et al. revealed that quercetin, by declining the expression of UBE2S, which is highly expressed in malignant cancers contributed to cell motility via epithelial-mesenchymal transition signaling, inhibits the invasion of cervical cancer cells [80].

\section{Other cancers}

Tummala et al. showed that quercetin downregulated AR-V7 and hnRNPA1 expression, antagonized androgen receptor signaling, and promoted the sensitization of enzalutamide-resistant prostate cancer cells to enzalutamide treatment [81]. In the case of melanoma therapy, it was recently stated that quercetin inhibited the viability of A375SM melanoma cells through apoptosis induction. Additionally, it reduced the tumor volume in vivo and decreased the proliferation of cancerous cells in vitro [82]. Moreover, quercetin is a potent anticancer agent for the treatment of brain tumors, such as glioblastoma multiforme, as reviewed by Tavana et el. [83]. In human papillary thyroid cancer cell line (B-CPAP) quercetin significantly decreased cell proliferation and promoted apoptosis through caspase activation. It also provoked cell apoptosis through Hsp90 expression that may be associated with the reduction of chymotrypsinlike proteasome activity. The elimination of chymotrypsin-like proteasome activity represses growth and led to cell death in thyroid cancer cells [59]. Since low bioavailability of quercetin, Quagliariello et al. were used a hyaluronic acid (HA) hydrogel as a carrier of quercetin and have explored the result of drug treatment alone or in combination to SNS-314 that is an anti-Aurora kinase in human medullary and papillary thyroid cancer cells. It was noted that HA acted as a ligand of CD44 which is sufficiently increased in various cancer cells and related to tumor progression $[84,85]$. On the other hand, incorporation of quercetin and SNS-314 caused a synergistic cytotoxic influence on both cell lines with an important reduction of the IC50 value [85]. Wiśniewska and colleagues have demonstrated the impact of quercetin on the essential cytoskeletal elements, such as microfilaments, microtubules, cytoskeleton-driven processes and vimentin intermediate filaments in A549 non-small cell lung cancer cells. Their results revealed that quercetin induced apoptosis via the regulation of BCL2/BAX, also necrosis and mitotic catastrophe, and repressed the migratory of those cells. The disassembling influence of quercetin on vimentin filaments, microtubules, and microfilaments accompanied by its suppression effect on $\mathrm{N}$-cadherin and vimentin expression might be responsible for the reduced migration of A549 cells in reply to quercetin therapy. It is also reported that the probable mechanism underlying quercetin -induced mitotic disaster comprise the disturbance of mitotic microtubules results in monopolar spindle development, and subsequently the collapse of cytokinesis. They also proposed that quercetin can lead to the destruction of actin filaments leading to cytokinesis failure [86].

After $72 \mathrm{~h}$ treatment with $40 \mu \mathrm{M}$ quercetin, decreased cell viability and promoted apoptosis follow by necrosis was reported in prostate cancer (Pca) cells treated compare to untreated ones. In addition, quercetin has impressing effects on the mitochondrial integrity and also depending on oxidation situation of the cells, can serve as an antioxidant or as a pro-oxidant for balancing reactive oxygen species (ROS) production in $\mathrm{PCa}$ cells. According to this study, quercetin repressed $\mathrm{PCa}$ via alleviating cell survival, frustrating anti-apoptotic pathways and also participate in MAPK, Akt, and NF- $\mathrm{kB}$ signaling pathways in different $\mathrm{PCa}$ cell lines with p53 mutated or without p53 mutated. Collectively, this research declared quercetin via regulation of ROS, Akt, and NF- $\mathrm{kB}$ pathways show an anti-cancer effect and could be utilized as a chemotherapeutic medicine to promote clinical results of PCa cases [87].

Nwaeburu et al. have surveyed the profiling of miRNA expression in AsPC1 (Pancreatic cancer cell line) cells before and after treatment with quercetin and indicated quercetin induced miR-200b-3p expression. This miRNA has a significant role in the choice of a Pancreatic Ductal Adenocarcinoma (PDA) cell to offer either symmetric or asymmetric division through regulating Notch signaling [88]. Symmetric division causes two equal daughter 
cells and leads to exponential tumor growth but asymmetric cell division produce two different daughter cells and is presented through cancer stem cells(CSCs) for homeostasis [89-91]. Also, it was proved that miR-200b expressed highly in the normal pancreas cell and of course down-regulated in PDA cells [88, 92]. After treatment of PDA cell with quercetin, the expression level of miR-200 was modulated which resulting to cell fate control and repression of cancer initiation, proliferation, invasion $[88,93,94]$. Table 1 listed various studies on the anti-cancer effects of quercetin.

\section{Quercetin as novel therapy for ovarian cancer}

Ovarian cancer is one of the most prevalent types of women malignancies and is responsible for the most deaths among the gynecologic cancers. In this cancer, there are some of the risk factors such as age, family history, late menopause, and null parity whiles with the pregnancy and breastfeeding reduce the occurrence risk [95].

The biology of ovarian cancer differs from that of hematogenously metastasizing tumors because ovarian cancer cells primarily disseminate within the peritoneal cavity and are only superficially invasive. Nevertheless, since the rapidly proliferating tumors compress visceral organs and are only temporarily chemosensitive, ovarian carcinoma is a deadly disease [96] Ovarian cancers are separated into type I (low grade) and II (high-grade serous and carcinosarcoma) [97].

In the quest to produce medicines for cancer chemotherapy, Tiwari and colleagues investigated the effectiveness of the combination of drugs operating synergistically. They have studied the effect of Graphene oxide polyvinylpyrrolidone- quercetin -gefitinib (GO-PVP-QSR-GEF) on the ovarian cancer cells (PA-1). They illustrated that quercetin could has a synergic effect on gefitinib anticancer property on PA-1 cells, an ovarian cancer originated cell line [98]. In addition, it revealed that quercetin decreased the cell viability of PA- 1 cells in a dose and time-dependent procedure. It is worth noticing that they reported $75 \mu \mathrm{M}$ of quercetin as optimal dose. The molecular mechanism evaluation following the promoting apoptotic effect of quercetin in PA-1 cell showed that quercetin regulates the intrinsic apoptotic pathway that lead to reducing of the anti-apoptotic molecules such as $\mathrm{Bcl}-2, \mathrm{Bcl}-\mathrm{xL}$ while increased the expression level of proapoptotic molecules such as caspase-3, caspase-9, cyto-c, Bid, Bad, and Bax [99]. Doxorubicin is a chemotherapeutic agent that used in various cancer including ovarian, thyroid, breast, and lung cancer but a notable unfavorable effect such as cardiotoxicity limits its use [100]. To overcome this limit, scientific used quercetin as a chemosensitizer in combination with doxorubicin. Survey in ovarian cancer xenograft model indicated that quercetin is able to attenuate the doxorubicin-induced cardiotoxicity. Ren et al. investigated the function of quercetin on the proliferation and apoptosis of ovarian cancer cell line SKOV-3 in order to present an experimental foundation for the clinical utilization of quercetin in the therapy of ovarian cancer. Quercetin repressed the proliferation of ovarian cancer SKOV-3 cells in a time- and dose-dependent manner. Also, quercetin could promote the apoptosis of SKOV-3 cells and decreased the survivin protein expression. Flow cytometry report revealed that quercetin provoked SKOV-3 cells cycle arrest in the G0/G1 and a notable reduction in the rate of cells at the G2/M phase; moreover, the apoptosis percentage was recognized to boost resulting quercetin therapy [101].

Current evidences about quercetin effects on enhancing the sensitivity of tumor radiotherapy have revealed that quercetin could enhance the effect of radiationinduced cell death. The combination quercetin treatment with X-irradiation increased the DNA damages and created common apoptotic cell death; as well resulted in increasing of Bax level and decreasing of Bcl-2 level in ovarian cancer cell lines (OV2008 and SKOV3) compared to cells presented to quercetin or X-rays alone. In addition, a combination of quercetin treatment with radiation remarkably suppressed the growth of tumors, followed by the induction of p53, CCAAT/enhancer-binding protein homologous protein (CHOP) that is the ER stress biomarker, and $\gamma$-H2AX. Conclusively, these outcomes showed that quercetin served as a hopeful radiosensitizer by p53-dependent ER stress signals in human ovarian tumor xenograft model [102].

Quercetin can result in stimulate the ER stress pathway that lead to the cause of cell death and apoptosis [103-105]. Quercetin provoked the ER stress by directly provoking apoptosis via raised levels of GRP78, CHOP that both of them are markers of ER stress and cleaved caspase 4 that has been recognized as a principal performer in ER-induced apoptosis in ovarian cancer cell lines and primary ovarian cancer cells $[20,106]$. In order to explore the mechanism of quercetin-induced ER stress and apoptosis, some researchers have focused on the p-STAT3/Bcl-2 axis, which was verified to be able to modulate caspase-cleavage to reduce apoptosis. The outcomes determined that quercetin-induced ER stress is associated with the mitochondrial apoptosis pathway via activation of the $\mathrm{p}-\mathrm{STAT} 3 / \mathrm{Bcl}-2$ axis. Unexpectedly, the repression of ER stress could not repeal quercetininduced apoptosis. Additional functional investigations exhibited that quercetin-induced ER stress could stimulate protective autophagy simultaneously by arousing the p-STAT3/Bcl-2 axis in this manner. Furthermore, 3-MA, an autophagy scavenger, was presented to improve 


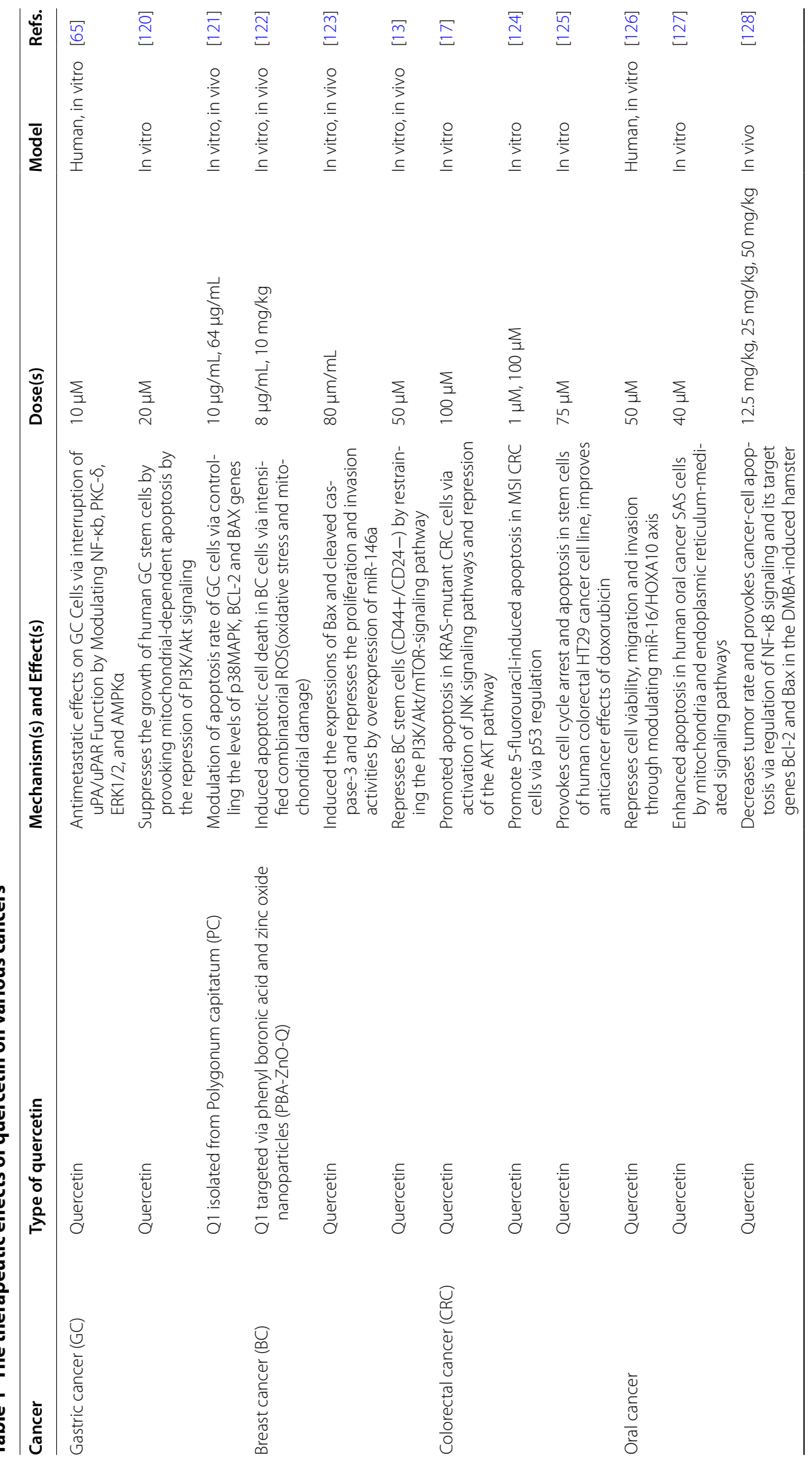




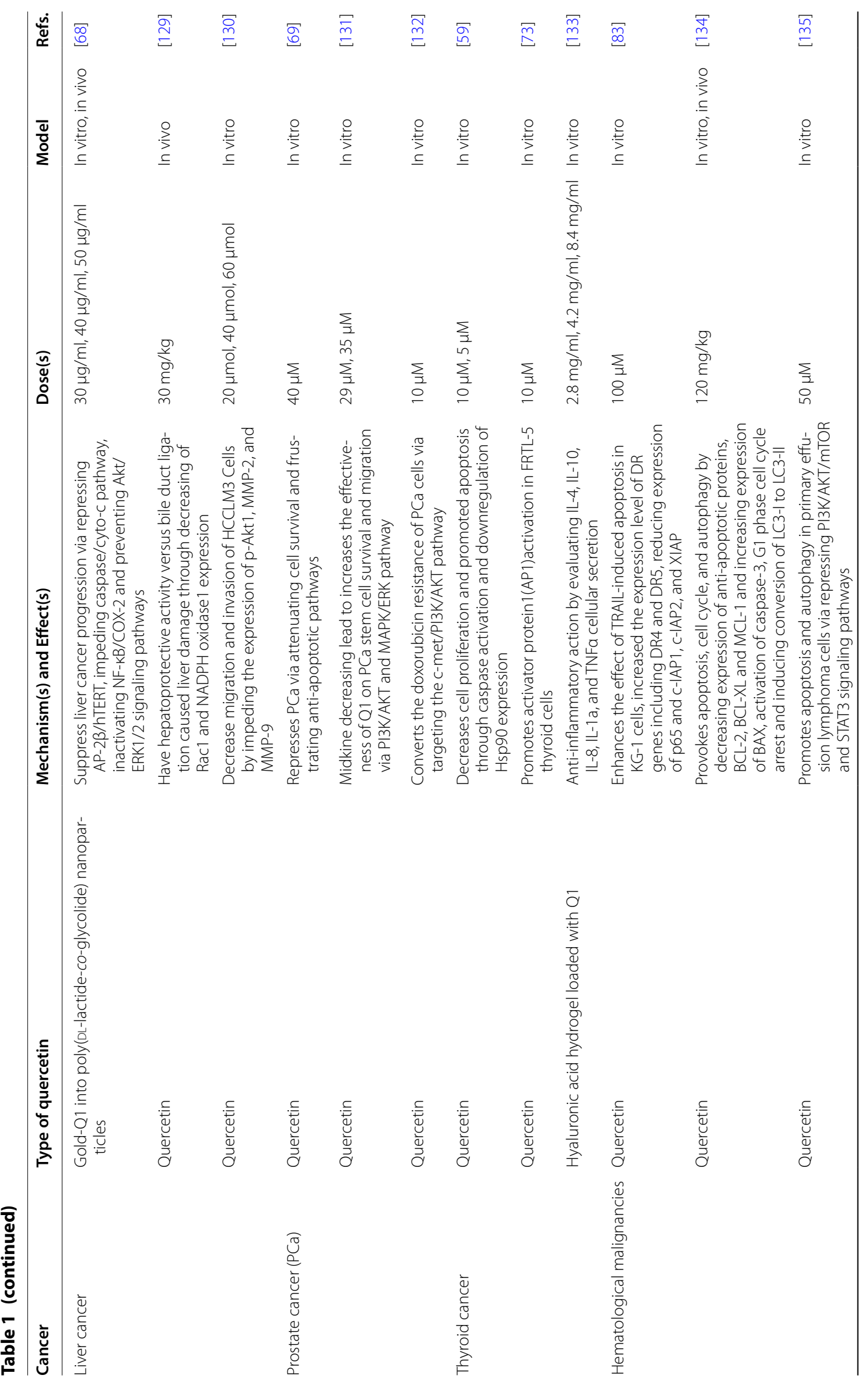




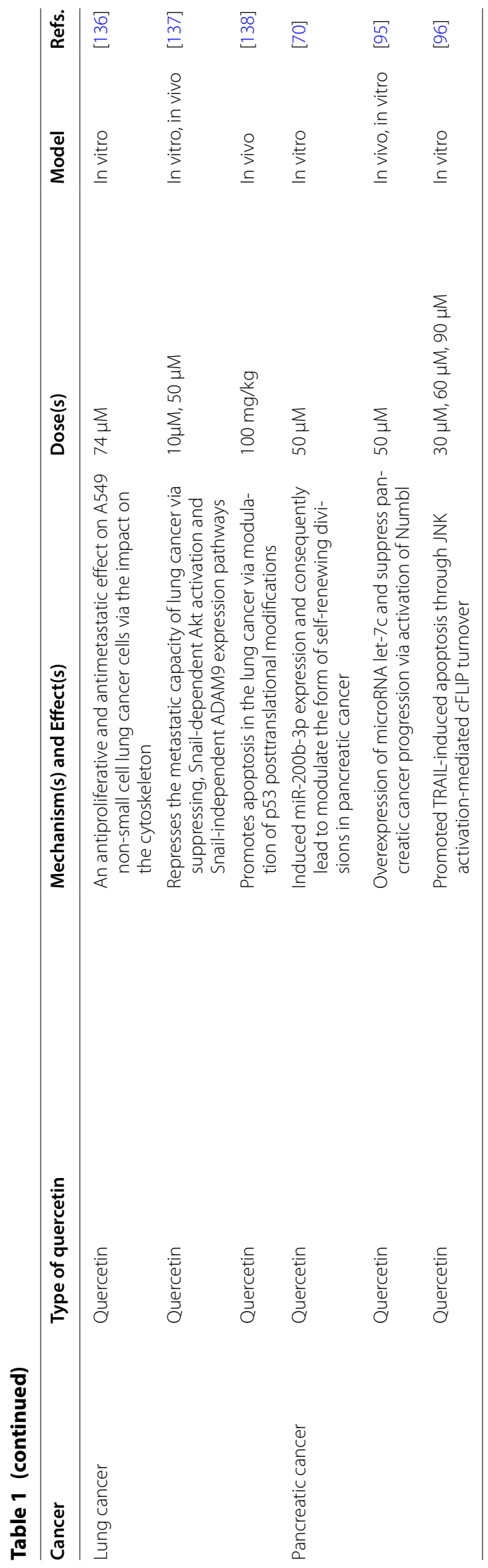


quercetin's anticancer influences in an ovarian cancer mice xenograft model. Ultimately, this study introduced a unique function of ER stress as a "double edge sword" engaging in quercetin-induced apoptosis in ovarian cancer and might present a new viewpoint to recognize in clinical investigations of biological modifiers that may evade drug resistance in subjects through targeting protective autophagy pathways [20].

Quercetin, because of its little absorption in gastrointestinal tract, enormous first pass metabolism, gastrointestinal instability, low hydrophilicity, and poor solubility, is a challenging pharmacological agent to be delivered [107]. Its oral bioavailability has been illustrated to be less than $17 \%$ in animals and less than $2 \%$ in human, hence restricting its clinical use utilizing conventional dosage forms $[108,109]$. Therefore, an ameliorated quercetin oral formulation is needed with higher efficacy and better bioavailability.

Nanoformulation-based approaches for potential therapeutic molecules delivery have been shown to ameliorate the efficiency of such molecules, which otherwise suffer from particular restrictions [110-112]. Various delivery systems have been demonstrated for quercetin, including microemulsion, nanoparticles, liposomes, and solid lipid nanoparticles for different applications, including in aging and neurodegenerative disease [109, 113-115].

Hydrophobic drugs that are encapsulated into nanoparticles become completely dispersible in water and injectable intravenously. Anticancer drugs which are delivered by biodegradable polymeric nanoparticles, as great candidates for anticancer drug delivery systems [116], are currently used in clinical practice. Poly(3caprolactone)/poly(ethylene glycol)(PCL/PEG) block copolymers are easy to produce, amphiphilic and biodegradable, indicating hopeful application in drug delivery systems [117]. Recently, utilizing the PCL/PEG nanoparticles for encapsulating drugs to ameliorate the water solubility of hydrophobic drugs has attracted attentions. Gao and colleagues evaluated quercetin nanoformulation effects on the colony formation ability and proliferation of ovarian cells [95]. Encapsulated quercetin into biodegradable monomethoxy poly (ethylene glycol)-poly( $\varepsilon$ caprolactone) (MPEG-PCL) micelles and attempted to yield proof-of-principle for the treatment of ovarian cancer with this quercetin nano-formulation. These quercetin loaded MPEG-PCL (QU/MPEG-PCL) micelles with drug loading of $6.9 \%$ had a mean particle size of $36 \mathrm{~nm}$, providing the complete quercetin dispersion in water.

The growth of A2780S ovarian cancer cells was suppressed in vitro by quercetin on a concentration-dependent approach. In addition, intravenously administered QU/MPEG-PCL micelles remarkably inhibited the xenograft A2780S ovarian tumors growth in vivo by suppressing angiogenesis and inducing apoptosis of cancer cells, which is correlated with caspase-3 and -9 activation. In addition, alteration of mitochondrial trans-membrane potential, downregulation of Bcl-2 and MCL-1, and upregulation of Bax were seen, indicating that apoptosis induction effects is via the mitochondrial apoptotic pathways. Anti-proliferative effect of quercetin against A2780S cells was through decreasing phosphorylated Akt as well as phosphorylated p44/42 mitogen-activated protein kinase. Therefore, QU/MPEG-PCL micelles were shown to be novel quercetin nano-formulations with a beneficial application in the treatment of ovarian cancer [95].

In order to show the susceptibility of cisplatin-resistant ovarian cancer cells to quercetin and anticancer properties of this compound, Long et al. conducted in vivo and in vitro studies on the impact of PEGylated liposomal quercetin (Lipo-Que) on cisplatin-resistant (A2780cp) and cisplatin-sensitive (A2780s) human ovarian cancer models [118]. The findings revealed that Lipo-Que induced cell cycle arrest as well as apoptosis, and suppressed cell proliferation in both A2780cp and A2780s cells in vitro. Additionally, anticancer feature of LipoQue was assessed in both cisplatin-resistant and cisplatin-sensitive human ovarian tumor xenograft models in nude mice. Compared to normal saline, blank liposomes and free quercetin, Lipo-Que considerably inhibited tumor growth in both models. Moreover, immunofluorescence and immunohistochemistry methods demonstrated that Lipo-Que suppressed tumors proliferation, reduced microvessel density, and induced apoptosis in both A2780cp and A2780s tumor models. Thus, LipoQue was proposed to be an efficient formulation for tumor growth inhibition in both cisplatin-resistant and cisplatin-sensitive human ovarian cancers [118].

Teekaraman and his colleagues conducted an in vitro study and illustrated that quercetin, at dose of 50 and $75 \mu \mathrm{M}$, is able to induce apoptosis in metastatic ovarian cancer cells leading to inhibit their growth [99]. On the other hand, it was recently reported that co-treatment with quercetin and selenium have synergistic radioprotective and cytoprotective impacts on oxidative stress in endometrial adenocarcinoma cells [119]. Table 2 summarized various studies quercetin in ovarian cancer.

\section{Conclusion}

It is widely accepted that ovarian cancer is the main cause of deaths associated with gynecology cancer across the world. Utilizing compounds derived from plants has been extensively considered for the treatment of cancer. According to the obtained evidences, quercetin can prevent ovarian cancer through a couple of mechanisms 


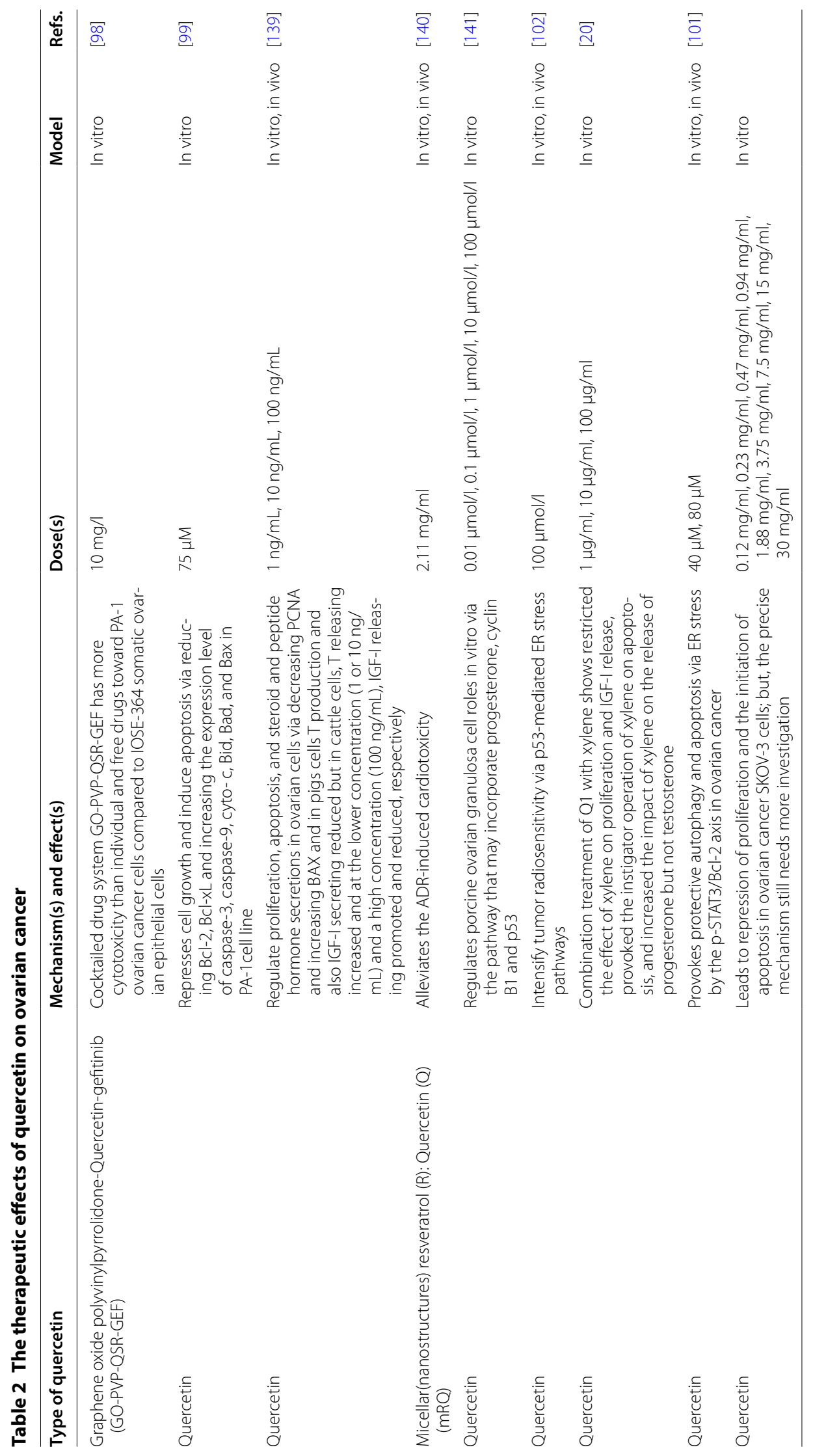


including anti-inflammation, pro-oxidation, anti-proliferation, and cell cycle arrest. Moreover, this natural compound is capable of strengthening the impacts of other chemotherapeutic medications. Further studies should also perform to illustrate its detailed mechanisms of action regarding ovarian cancer. Besides various advantages, utilization of quercetin is associated with different limitations such as very poor bioavailability, poor absorption, rapid metabolism, chemical instability, and rapid systemic elimination. Utilization of quercetin analogs and targeting quercetin by nanotechnology-based approaches may therefore overcome these limitations. Hence, it seems that these platforms can potentially open new horizons in the utilization of quercetin as powerful therapeutic agent alone or in combination with other drugs in the treatment of different types of cancer such as ovarian cancer. So far, there have not been clinical studies to assess the anti-ovarian cancer effects of quercetin. It seems that clinical studies will help us to assess the safety and potency of this drug for the treatment of ovarian cancer.

\section{Abbreviations \\ COX: Cyclooxygenase; CRP: C-reactive protein; CRC: Colorectal cancer; GC: Gastric cancer; JNK: N-terminal kinase; PBA: Phenyl boronic acid; ROS: Reactive oxygen species; uPA: Urokinase plasminogen activator.}

\section{Acknowledgements}

Not applicable.

\section{Authors' contributions}

HM contributed in conception, design and drafting of the manuscript. ER and AS, AV, ZSH, FF, YGH, MA, ASH, SH, and SM contributed in data collection and manuscript drafting. All authors read and approved the final manuscript.

\section{Funding}

Not applicable.

\section{Availability of data and materials \\ Not applicable.}

Ethics approval and consent to participate

Not applicable.

\section{Consent for publication}

Not applicable.

\section{Competing interests}

The authors declare that they have no competing interests.

\footnotetext{
Author details

${ }^{1}$ Department of Medical Biotechnology, School of Advanced Medical Sciences and Technologies, Shiraz University of Medical Sciences, Shiraz, Iran. ${ }^{2}$ Department of Nanotechnology, Faculty of Biological Sciences, Tarbiat Modares University, Tehran, Iran. ${ }^{3}$ Pharmaceutical Sciences Research Center, Shiraz University of Medical Sciences, Shiraz, Iran. ${ }^{4}$ Student Research Committee, Shiraz University of Medical Sciences, Shiraz, Iran. ${ }^{5}$ Research Center for Biochemistry and Nutrition in Metabolic Diseases, Institute for Basic Sciences, Kashan University of Medical Sciences, Kashan, I.R. of Iran. ${ }^{6}$ Department of Gynecology and Obstetrics, Ramsar Campus, Mazandaran University of Medical Sciences, Sari, Iran. ${ }^{7}$ Department of Pharmaceutical Biotechnology, School of Pharmacy and Pharmaceutical Sciences Research Center, Shiraz
}

University of Medical Sciences, Shiraz, Iran. ${ }^{8}$ Department of Surgery, Kashan University of Medical Sciences, Kashan, Iran. ${ }^{9}$ Division of General Internal Medicine, Toronto General Hospital, Toronto, ON, Canada. ${ }^{10}$ The Advocate Center for Clinical Research, Ayatollah Yasrebi Hospital, Kashan, Iran.

Received: 10 November 2019 Accepted: 29 February 2020

Published online: 10 March 2020

\section{References}

1. Shafabakhsh R, Asemi Z. Quercetin: a natural compound for ovarian cancer treatment. J Ovarian Res. 2019;12(1):55.

2. Jayson GC, Kohn EC, Kitchener HC, Ledermann JA. Ovarian cancer. Lancet (London, England). 2014;384(9951):1376-88.

3. Parvaresh A, Razavi R, Rafie N, Ghiasvand R, Pourmasoumi M, Miraghajani M. Quercetin and ovarian cancer: an evaluation based on a systematic review. J Res Med Sci. 2016;21:34.

4. Seidman JD, Kurman RJ: Pathology of ovarian carcinoma. Hematol Oncol Clin N Am 2003 17(4):909-25, vii.

5. Thomasset SC, Berry DP, Garcea G, Marczylo T, Steward WP, Gescher AJ. Dietary polyphenolic phytochemicals-promising cancer chemopreventive agents in humans? A review of their clinical properties. Int J Cancer. 2007;120(3):451-8.

6. Metodiewa D, Jaiswal AK, Cenas N, Dickancaite E, Segura-Aguilar J. Quercetin may act as a cytotoxic prooxidant after its metabolic activation to semiquinone and quinoidal product. Free Radical Biol Med. 1999:26(1-2):107-16.

7. Harwood M, Danielewska-Nikiel B, Borzelleca JF, Flamm GW, Williams GM, Lines TC. A critical review of the data related to the safety of quercetin and lack of evidence of in vivo toxicity, including lack of genotoxic/carcinogenic properties. Food Chem Toxicol. 2007:45(11):2179-205.

8. Hirpara KV, Aggarwal P, Mukherjee AJ, Joshi N, Burman AC. Quercetin and its derivatives: synthesis, pharmacological uses with special emphasis on anti-tumor properties and prodrug with enhanced bioavailability. Anti-Cancer Agents Med Chem (Formerly Current Medicinal Chemistry-Anti-Cancer Agents). 2009;9(2):138-61.

9. Boots AW, Haenen GR, Bast A. Health effects of quercetin: from antioxidant to nutraceutical. Eur J Pharmacol. 2008:585(2-3):325-37.

10. Panche AN, Diwan AD, Chandra SR. Flavonoids: an overview. J Nutr Sci. 2016:5:e47.

11. Gates MA, Vitonis AF, Tworoger SS, Rosner B, Titus-Ernstoff L, Hankinson SE, Cramer DW. Flavonoid intake and ovarian cancer risk in a population-based case-control study. Int J Cancer. 2009;124(8):1918-25.

12. Song NR, Chung MY, Kang NJ, Seo SG, Jang TS, Lee HJ, Lee KW. Quercetin suppresses invasion and migration of H-Ras-transformed MCF10A human epithelial cells by inhibiting phosphatidylinositol 3-kinase. Food Chem. 2014;142:66-71.

13. Li X, Zhou N, Wang J, Liu Z, Wang X, Zhang Q, Liu Q, Gao L, Wang R. Quercetin suppresses breast cancer stem cells (CD44+/CD24-) by inhibiting the PI3K/Akt/mTOR-signaling pathway. Life Sci. 2018;196:56-62.

14. Baby B, Antony P, Vijayan R. Interactions of quercetin with receptor tyrosine kinases associated with human lung carcinoma. Nat Prod Res. 2018;32(24):2928-31.

15. Huang D-Y, Dai Z-R, Li W-M, Wang R-G, Yang S-M. Inhibition of EGF expression and NF-KB activity by treatment with quercetin leads to suppression of angiogenesis in nasopharyngeal carcinoma. Saudi J Biol Sci. 2018;25(4):826-31.

16. Polukonova NV, Navolokin NA, Bucharskaya AB, Mudrak DA, Baryshnikova MA, Stepanova EV, Solomko ES, Polukonova AV, Maslyakova GN. The apoptotic activity of flavonoid-containing Gratiola officinalis extract in cell cultures of human kidney cancer. Russ Open Med J. 2018. https:// doi.org/10.15275/rusomj.2018.0402.

17. Yang Y, Wang T, Chen D, Ma Q, Zheng Y, Liao S, Wang Y, Zhang J. Quercetin preferentially induces apoptosis in KRAS-mutant colorectal cancer cells via JNK signaling pathways. Cell Biol Int. 2019;43(2):117-24.

18. Sharmila G, Bhat F, Arunkumar R, Elumalai P, Singh PR, Senthilkumar $\mathrm{K}$, Arunakaran J. Chemopreventive effect of quercetin, a natural 
dietary flavonoid on prostate cancer in in vivo model. Clin Nutr. 2014;33(4):718-26.

19. Lee J, Han S-I, Yun J-H, Kim JH. Quercetin 3-O-glucoside suppresses epidermal growth factor-induced migration by inhibiting EGFR signaling in pancreatic cancer cells. Tumor Biol. 2015;36(12):9385-93.

20. Liu Y, Gong W, Yang Z, Zhou X, Gong C, Zhang T, Wei X, Ma D, Ye F, Gao Q. Quercetin induces protective autophagy and apoptosis through ER stress via the $\mathrm{p}-\mathrm{STAT} 3 / \mathrm{BCl}-2$ axis in ovarian cancer. Apoptosis. 2017;22(4):544-57.

21. Schulz M, Lahmann PH, Boeing H, Hoffmann K, Allen N, Key TJ, Bingham S, Wirfalt E, Berglund G, Lundin E, et al. Fruit and vegetable consumption and risk of epithelial ovarian cancer: the European Prospective Investigation into Cancer and Nutrition. Cancer Epidemiol Biomark Prev. 2005;14(11 Pt 1):2531-5.

22. Cassidy A, Huang T, Rice MS, Rimm EB, Tworoger SS. Intake of dietary flavonoids and risk of epithelial ovarian cancer. Am J Clin Nutr. 2014;100(5):1344-51.

23. Vargas AJ, Burd R. Hormesis and synergy: pathways and mechanisms of quercetin in cancer prevention and management. Nutr Rev. 2010;68(7):418-28.

24. Williamson G, Day AJ, Plumb GW, Couteau D. Human metabolic pathways of dietary flavonoids and cinnamates. Biochem Soc Trans. 2000;28(2):16-22.

25. Falcao SI, Vale N, Gomes P, Domingues MR, Freire C, Cardoso SM, VilasBoas M. Phenolic profiling of Portuguese propolis by LC-MS spectrometry: uncommon propolis rich in flavonoid glycosides. Phytochem Anal PCA. 2013;24(4):309-18.

26. Popova MP, Chinou IB, Marekov IN, Bankova VS. Terpenes with antimicrobial activity from Cretan propolis. Phytochemistry. 2009;70(10):1262-71.

27. Lakhanpal P, Rai DK. Quercetin: a versatile flavonoid. Internet J Med Update. 2007;2(2):22-37.

28. Ferry DR, Smith A, Malkhandi J, Fyfe DW, deTakats PG, Anderson D, Baker J, Kerr DJ. Phase I clinical trial of the flavonoid quercetin: pharmacokinetics and evidence for in vivo tyrosine kinase inhibition. Clin Cancer Res. 1996;2(4):659-68.

29. Erlund I, Kosonen T, Alfthan G, Maenpaa J, Perttunen K, Kenraali J, Parantainen J, Aro A. Pharmacokinetics of quercetin from quercetin aglycone and rutin in healthy volunteers. Eur J Clin Pharmacol. 2000;56(8):545-53.

30. Graefe EU, Wittig J, Mueller S, Riethling AK, Uehleke B, Drewelow B, Pforte $\mathrm{H}$, Jacobasch G, Derendorf H, Veit M. Pharmacokinetics and bioavailability of quercetin glycosides in humans. J Clin Pharmacol. 2001;41(5):492-9.

31. Pratheeshkumar P, Budhraja A, Son YO, Wang X, Zhang Z, Ding S, Wang L, Hitron A, Lee JC, Xu M, et al. Quercetin inhibits angiogenesis mediated human prostate tumor growth by targeting VEGFR- 2 regulated AKT/mTOR/P70S6K signaling pathways. PLoS ONE. 2012;7(10):e47516.

32. Begum AN, Terao J. Protective effect of quercetin against cigarette tar extract-induced impairment of erythrocyte deformability. J Nutr Biochem. 2002;13(5):265-72.

33. Warren CA, Paulhill KJ, Davidson LA, Lupton JR, Taddeo SS, Hong MY, Carroll RJ, Chapkin RS, Turner ND. Quercetin may suppress rat aberrant crypt foci formation by suppressing inflammatory mediators that influence proliferation and apoptosis. J Nutr. 2009;139(1):101-5.

34. Xiao X, Shi D, Liu L, Wang J, Xie X, Kang T, Deng W. Quercetin suppresses cyclooxygenase-2 expression and angiogenesis through inactivation of P300 signaling. PLoS ONE. 2011;6(8):e22934.

35. Chun OK, Chung SJ, Claycombe KJ, Song WO. Serum C-reactive protein concentrations are inversely associated with dietary flavonoid intake in US adults. J Nutr. 2008;138(4):753-60.

36. Garcia-Mediavilla V, Crespo I, Collado PS, Esteller A, Sanchez-Campos S, Tunon MJ, Gonzalez-Gallego J. The anti-inflammatory flavones quercetin and kaempferol cause inhibition of inducible nitric oxide synthase, cyclooxygenase-2 and reactive C-protein, and down-regulation of the nuclear factor kappaB pathway in Chang Liver cells. Eur J Pharmacol. 2007:557(2-3):221-9.

37. Mamani-Matsuda M, Kauss T, Al-Kharrat A, Rambert J, Fawaz F, Thiolat D, Moynet D, Coves S, Malvy D, Mossalayi MD. Therapeutic and preventive properties of quercetin in experimental arthritis correlate with decreased macrophage inflammatory mediators. Biochem Pharmacol. 2006:72(10):1304-10.
38. Guardia T, Rotelli AE, Juarez AO, Pelzer LE. Anti-inflammatory properties of plant flavonoids. Effects of rutin, quercetin and hesperidin on adjuvant arthritis in rat. Farmaco. 2001;56(9):683-7.

39. Askari G, Ghiasvand R, Feizi A, Ghanadian SM, Karimian J. The effect of quercetin supplementation on selected markers of inflammation and oxidative stress. J Res Med Sci. 2012;17(7):637-41.

40. Javadi F, Eghtesadi S, Ahmadzadeh A, Aryaeian N, Zabihiyeganeh M, Foroushani AR, Jazayeri S. The effect of quercetin on plasma oxidative status, C-reactive protein and blood pressure in women with rheumatoid arthritis. Int J Prev Med. 2014;5(3):293-301.

41. Ahmad NS, Farman M, Najmi MH, Mian KB, Hasan A. Pharmacological basis for use of Pistacia integerrima leaves in hyperuricemia and gout. J Ethnopharmacol. 2008;117(3):478-82.

42. Ramos FA, Takaishi Y, Shirotori M, Kawaguchi Y, Tsuchiya K, Shibata H, Higuti T, Tadokoro T, Takeuchi M. Antibacterial and antioxidant activities of quercetin oxidation products from yellow onion (Allium cepa) skin. J Agric Food Chem. 2006;54(10):3551-7.

43. Cushnie T, Lamb A. Antimicrobial activity of flavonoids. Int J Antimicrob Agents. 2006;26:343-56.

44. Okamoto T. Safety of quercetin for clinical application. Int J Mol Med. 2005;16(2):275-8.

45. Sak K. Site-specific anticancer effects of dietary flavonoid quercetin. Nutr Cancer. 2014;66(2):177-93.

46. Poor M, Zrinyi Z, Koszegi T. Structure related effects of flavonoid aglycones on cell cycle progression of HepG2 cells: Metabolic activation of fisetin and quercetin by catechol-O-methyltransferase (COMT). Biomed Pharmacother Biomed Pharmacother. 2016;83:998-1005.

47. O'Leary KA, Day AJ, Needs PW, Mellon FA, O'Brien NM, Williamson G. Metabolism of quercetin-7- and quercetin-3-glucuronides by an in vitro hepatic model: the role of human beta-glucuronidase, sulfotransferase, catechol-O-methyltransferase and multi-resistant protein 2 (MRP2) in flavonoid metabolism. Biochem Pharmacol. 2003;65(3):479-91.

48. Shirai M, Kawai Y, Yamanishi R, Kinoshita T, Chuman H, Terao J. Effect of a conjugated quercetin metabolite, quercetin 3-glucuronide, on lipid hydroperoxide-dependent formation of reactive oxygen species in differentiated PC-12 cells. Free Radic Res. 2006:40(10):1047-53.

49. Krol W, Dworniczak S, Pietsz G, Czuba ZP, Kunicka M, Kopacz M, Nowak D. Synthesis and tumoricidal activity evaluation of new morin and quercetin sulfonic derivatives. Acta Pol Pharm. 2002;59(1):77-9.

50. Kim MK, Park KS, Lee C, Park HR, Choo H, Chong Y. Enhanced stability and intracellular accumulation of quercetin by protection of the chemically or metabolically susceptible hydroxyl groups with a pivaloxymethyl (POM) promoiety. J Med Chem. 2010;53(24):8597-607.

51. lacopetta D, Grande F, Caruso A, Mordocco RA, Plutino MR, Scrivano L, Ceramella J, Muia N, Saturnino C, Puoci F, et al. New insights for the use of quercetin analogs in cancer treatment. Future Med Chem. 2017:9(17):2011-28.

52. Srivastava S, Somasagara RR, Hegde M, Nishana M, Tadi SK, Srivastava M, Choudhary B, Raghavan SC. Quercetin, a natural flavonoid interacts with DNA, arrests cell cycle and causes tumor regression by activating mitochondrial pathway of apoptosis. Sci Rep. 2016:6:24049.

53. Yoshida M, Sakai T, Hosokawa N, Marui N, Matsumoto K, Fujioka A, Nishino $\mathrm{H}$, Aoike A. The effect of quercetin on cell cycle progression and growth of human gastric cancer cells. FEBS Lett. 1990;260(1):10-3.

54. Choi J-A, Kim J-Y, Lee J-Y, Kang C-M, Kwon H-J, Yoo Y-D, Kim T-W, Lee Y-S, Lee S-J. Induction of cell cycle arrest and apoptosis in human breast cancer cells by quercetin. Int J Oncol. 2001;19(4):837-44.

55. Richter M, Ebermann R, Marian B. Quercetin-induced apoptosis in colorectal tumor cells: possible role of EGF receptor signaling. Nutr Cancer. 1999;34(1):88-99.

56. EIAttar T, Virji AS. Modulating effect of resveratrol and quercetin on oral cancer cell growth and proliferation. Anticancer Drugs. 1999;10(2):187-93.

57. Wang G, Zhang J, Liu L, Sharma S, Dong Q. Quercetin potentiates doxorubicin mediated antitumor effects against liver cancer through p53/ BCl-xl. PLOS ONE. 2012;7(12):e51764.

58. Nair HK, Rao KV, Aalinkeel R, Mahajan S, Chawda R, Schwartz SA. Inhibition of prostate cancer cell colony formation by the flavonoid quercetin correlates with modulation of specific regulatory genes. Clin Diagn Lab Immunol. 2004;11(1):63-9. 
59. Mutlu Altundağ E, Kasacı T, Yılmaz AM, Karademir B, Koçtürk S, Taga Y, Yalçın AS. Quercetin-induced cell death in human papillary thyroid cancer (B-CPAP) cells. J Thyroid Res. 2016. https://doi. org/10.1155/2016/9843675.

60. Lee T-J, Kim OH, Kim YH, Lim JH, Kim S, Park J-W, Kwon TK. Quercetin arrests G2/M phase and induces caspase-dependent cell death in U937 cells. Cancer Lett. 2006;240(2):234-42.

61. Angst E, Park JL, Moro A, Lu Q-Y, Lu X, Li G, King J, Chen M, Reber HA, Go $V L W$. The flavonoid quercetin inhibits pancreatic cancer growth in vitro and in vivo. Pancreas. 2013;42(2):223.

62. Zheng S-Y, Li Y, Jiang D, Zhao J, Ge J-F. Anticancer effect and apoptosis induction by quercetin in the human lung cancer cell line A-549. Mol Med Rep. 2012;5(3):822-6.

63. Bazuro GE, Torino F, Gasparini G, Capurso L. Chemoprevention in gastrointestinal adenocarcinoma: for few but not for all? Minerva Gastroenterol Dietol. 2008;54(4):429-44.

64. Nasrabadi NN, Ataee R, Abediankenari S, Shokrzadeh M, Najafi M, Hoseini SV, Jan HH. Expression of MT2 receptor in patients with gastric adenocarcinoma and its relationship with clinicopathological features. J Gastrointest Cancer. 2014:45(1):54-60.

65. Xi L, Zhang Y, Kong S, Liang W. miR-34 inhibits growth and promotes apoptosis of osteosarcoma in nude mice through targetly regulating TGIF2 expression. Biosci Rep. 2018;38(3):BSR20180078.

66. Lievre A, Bachet J-B, Boige V, Cayre A, Le Corre D, Buc E, Ychou M, Bouché $\mathrm{O}$, Landi B, Louvet C. KRAS mutations as an independent prognostic factor in patients with advanced colorectal cancer treated with cetuximab. J Clin Oncol. 2008;26(3):374-9.

67. Tejpar S, Celik I, Schlichting M, Sartorius U, Bokemeyer C, Van Cutsem E. Association of KRAS G13D tumor mutations with outcome in patients with metastatic colorectal cancer treated with first-line chemotherapy with or without cetuximab. J Clin Oncol. 2012;30(29):3570-7.

68. Ren K-W, Li Y-H, Wu G, Ren J-Z, Lu H-B, Li Z-M, Han X-W. Quercetin nanoparticles display antitumor activity via proliferation inhibition and apoptosis induction in liver cancer cells. Int J Oncol. 2017;50(4):1299-311.

69. Szymczyk A, Macheta A, Podhorecka M. Abnormal microRNA expression in the course of hematological malignancies. Cancer Manag Res. 2018;10:4267-77.

70. Ramdass B, Chowdhary A, Koka PS. Hematological malignancies: disease pathophysiology of leukemic stem cells. J Stem Cells. 2013;8(3-4):151-87.

71. He D, Guo X, Zhang E, Zi F, Chen J, Chen Q, Lin X, Yang L, Li Y, Wu W, et al. Quercetin induces cell apoptosis of myeloma and displays a synergistic effect with dexamethasone in vitro and in vivo xenograft models. Oncotarget. 2016;7(29):45489-99.

72. Ma Y, Jin Z, Huang J, Zhou S, Ye H, Jiang S, Yu K. Quercetin suppresses the proliferation of multiple myeloma cells by down-regulating IQ motif-containing GTPase activating protein 1 expression and extracellular signal-regulated kinase activation. Leuk Lymphoma. 2014;55(11):2597-604.

73. Granato M, Rizzello C, Gilardini Montani MS, Cuomo L, Vitillo M, Santarelli R, Gonnella R, D'Orazi G, Faggioni A, Cirone M. Quercetin induces apoptosis and autophagy in primary effusion lymphoma cells by inhibiting PI3K/AKT/mTOR and STAT3 signaling pathways. J Nutr Biochem. 2017:41:124-36.

74. Ha EJ, Kim KY, Kim CE, Jun DY, Kim YH. Enhancement of quercetininduced apoptosis by cotreatment with autophagy inhibitor is associated with augmentation of bak-dependent mitochondrial pathway in Jurkat T cells. Oxid Med Cell Longev. 2019;2019:7989276.

75. Naimi A, Entezari A, Hagh MF, Hassanzadeh A, Saraei R, Solali S. Quercetin sensitizes human myeloid leukemia KG-1 cells against TRAILinduced apoptosis. J Cell Physiol. 2019;234(8):13233-41.

76. Lim B, Allen JE, Prabhu W, Talekar MK, Finnberg NK, El-Deiry WS. Targeting TRAIL in the treatment of cancer: new developments. Expert Opin Ther Targets. 2015;19(9):1171-85.

77. Farrand L, Oh SW, Song YS, Tsang BK. Phytochemicals: a multitargeted approach to gynecologic cancer therapy. Biomed Res Int. 2014;2014:890141.

78. Amant F, Van Calsteren K, Halaska MJ, Beijnen J, Lagae L, Hanssens M, Heyns L, Lannoo L, Ottevanger NP, Vanden Bogaert W, et al. Gynecologic cancers in pregnancy: guidelines of an international consensus meeting. Int J Gynecol Cancer. 2009;19(Suppl 1):S1-12.
79. Benedet JL, Bender H, Jones H 3rd, Ngan HY, Pecorelli S. FIGO staging classifications and clinical practice guidelines in the management of gynecologic cancers FIGO Committee on Gynecologic Oncology. Int J Gynaecol Obstet. 2000;70(2):209-62.

80. Lin TH, Hsu WH, Tsai PH, Huang YT, Lin CW, Chen KC, Tsai IH, Kandaswami CC, Huang CJ, Chang GD, et al. Dietary flavonoids, luteolin and quercetin, inhibit invasion of cervical cancer by reduction of UBE2S through epithelial-mesenchymal transition signaling. Food Funct. 2017:8(4):1558-68.

81. Tummala R, Lou W, Gao AC, Nadiminty N. Quercetin targets hnRNPA1 to overcome enzalutamide resistance in prostate cancer cells. Mol Cancer Ther. 2017;16(12):2770-9.

82. Kim SH, Yoo ES, Woo JS, Han SH, Lee JH, Jung SH, Kim HJ, Jung JY. Antitumor and apoptotic effects of quercetin on human melanoma cells involving JNK/P38 MAPK signaling activation. Eur J Pharmacol. 2019;860:172568.

83. Tavana E, Mollazadeh H, Mohtashami E, Modaresi SMS, Hosseini A, Sabri H, Soltani A, Javid H, Afshari AR, Sahebkar A. Quercetin: a promising phytochemical for the treatment of glioblastoma multiforme. BioFactors. 2019. https://doi.org/10.1002/biof.1605.

84. Rosso F, Quagliariello V, Tortora C, Di Lazzaro A, Barbarisi A, laffaioli R. Cross-linked hyaluronic acid sub-micron particles: in vitro and in vivo biodistribution study in cancer xenograft model. J Mater Sci Mater Med. 2013;24(6):1473-81.

85. Quagliariello V, Armenia E, Aurilio C, Rosso F, Clemente O, de Sena G, Barbarisi M, Barbarisi A. New treatment of medullary and papillary human thyroid cancer: biological effects of hyaluronic acid hydrogel loaded with quercetin alone or in combination to an inhibitor of aurora kinase. J Cell Physiol. 2016;231 (8):1784-95.

86. Klimaszewska-Wiśniewska A, Hałas-Wiśniewska M, Izdebska M, Gagat M, Grzanka A, Grzanka D. Antiproliferative and antimetastatic action of quercetin on A549 non-small cell lung cancer cells through its effect on the cytoskeleton. Acta Histochem. 2017;119(2):99-112.

87. Ward AB, Mir H, Kapur N, Gales DN, Carriere PP, Singh S. Quercetin inhibits prostate cancer by attenuating cell survival and inhibiting antiapoptotic pathways. World J Surg Oncol. 2018;16(1):108.

88. Nwaeburu CC, Abukiwan A, Zhao Z, Herr I. Quercetin-induced miR$200 \mathrm{~b}-3 p$ regulates the mode of self-renewing divisions in pancreatic cancer. Mol Cancer. 2017;16(1):23.

89. Morrison SJ, Kimble J. Asymmetric and symmetric stem-cell divisions in development and cancer. Nature. 2006;441 (7097):1068.

90. Sugiarto S, Persson Al, Munoz EG, Waldhuber M, Lamagna C, Andor N, Hanecker P, Ayers-Ringler J, Phillips J, Siu J. Asymmetry-defective oligodendrocyte progenitors are glioma precursors. Cancer Cell. 2011;20(3):328-40.

91. Tang Y, Hou J, Li G, Song Z, Li X, Yang C, Liu W, Hu Y, Xu Y. ABCG2 regulates the pattern of self-renewing divisions in cisplatin-resistant non-small cell lung cancer cell lines. Oncol Rep. 2014;32(5):2168-74.

92. Gregory PA, Bert AG, Paterson EL, Barry SC, Tsykin A, Farshid G, Vadas MA, Khew-Goodall Y, Goodall GJ. The miR-200 family and miR-205 regulate epithelial to mesenchymal transition by targeting ZEB1 and SIP1. Nat Cell Biol. 2008;10(5):593.

93. Humphries B, Yang C. The microRNA-200 family: small molecules with novel roles in cancer development, progression and therapy. Oncotarget. 2015;6(9):6472.

94. Bracken CP, Li X, Wright JA, Lawrence DM, Pillman KA, Salmanidis M, Anderson MA, Dredge BK, Gregory PA, Tsykin A, et al. Genome-wide identification of miR-200 targets reveals a regulatory network controlling cell invasion. EMBO J. 2014;33(18):2040-56.

95. Gao X, Wang B, Wei X, Men K, Zheng F, Zhou Y, Zheng Y, Gou M, Huang M, Guo G. Anticancer effect and mechanism of polymer micelle-encapsulated quercetin on ovarian cancer. Nanoscale. 2012:4(22):7021-30.

96. Lengyel E. Ovarian cancer development and metastasis. Am J Pathol. 2010;177(3):1053-64

97. Cho KR, Shih I-M. Ovarian cancer. Annu Rev Pathol. 2009;4:287-313.

98. Tiwari H, Karki N, Pal M, Basak S, Verma RK, Bal R, Kandpal ND, Bisht G, Sahoo NG. Functionalized graphene oxide as a nanocarrier for dual drug delivery applications: the synergistic effect of quercetin and gefitinib against ovarian cancer cells. Colloids Surf B Biointerfaces. 2019;178:452-9. 
99. Teekaraman D, Elayapillai SP, Viswanathan MP, Jagadeesan A. Quercetin inhibits human metastatic ovarian cancer cell growth and modulates components of the intrinsic apoptotic pathway in PA-1 cell line. Chem Biol Interact. 2019;300:91-100.

100. Octavia Y, Tocchetti CG, Gabrielson KL, Janssens S, Crijns HJ, Moens AL. Doxorubicin-induced cardiomyopathy: from molecular mechanisms to therapeutic strategies. J Mol Cell Cardiol. 2012;52(6):1213-25.

101. Ren MX, Deng XH, Ai F, Yuan GY, Song HY. Effect of quercetin on the proliferation of the human ovarian cancer cell line SKOV-3 in vitro. Exp Ther Med. 2015;10(2):579-83.

102. Gong C, Yang Z, Zhang L, Wang Y, Gong W, Liu Y. Quercetin suppresses DNA double-strand break repair and enhances the radiosensitivity of human ovarian cancer cells via p53-dependent endoplasmic reticulum stress pathway. OncoTargets Ther. 2018;11:17.

103. Lee JH, Lee H-B, Jung GO, Oh JT, Park DE, Chae KM. Effect of quercetin on apoptosis of PANC-1 cells. J Korean Surg Soc. 2013;85(6):249-60.

104. Liu KC, Yen CY, Wu RSC, Yang JS, Lu HF, Lu KW, Lo C, Chen HY, Tang NY, Wu CC. The roles of endoplasmic reticulum stress and mitochondrial apoptotic signaling pathway in quercetin-mediated cell death of human prostate cancer PC-3 cells. Environ Toxicol. 2014;29(4):428-39.

105. Jakubowicz-Gil J, Langner E, Bądziul D, Wertel I, Rzeski W. Silencing of Hsp27 and Hsp72 in glioma cells as a tool for programmed cell death induction upon temozolomide and quercetin treatment. Toxicol Appl Pharmacol. 2013:273(3):580-9.

106. Yamamuro A, Kishino T, Ohshima Y, Yoshioka Y, Kimura T, Kasai A, Maeda S. Caspase-4 directly activates caspase-9 in endoplasmic reticulum stress-induced apoptosis in SH-SY5Y cells. J Pharmacol Sci. 2011;115:239-43.

107. Date AA, Nagarsenker MS, Patere S, Dhawan V, Gude RP, Hassan PA, Aswal V, Steiniger F, Thamm J, Fahr A. Lecithin-based novel cationic nanocarriers (Leciplex) II: improving therapeutic efficacy of quercetin on oral administration. Mol Pharm. 2011;8(3):716-26.

108. Gao L, Liu G, Wang X, Liu F, Xu Y, Ma J. Preparation of a chemically stable quercetin formulation using nanosuspension technology. Int J Pharm. 2011:404(1-2):231-7.

109. Li H, Zhao X, Ma Y, Zhai G, Li L, Lou H. Enhancement of gastrointestinal absorption of quercetin by solid lipid nanoparticles. J Control Release. 2009;133(3):238-44

110. Blum JS, Weller CE, Booth CJ, Babar IA, Liang X, Slack FJ, Saltzman WM. Prevention of K-Ras- and Pten-mediated intravaginal tumors by treatment with camptothecin-loaded PLGA nanoparticles. Drug Deliv Transl Res. 2011;1(5):383-94.

111. Yen FL, Wu TH, Lin LT, Cham TM, Lin CC. Naringenin-loaded nanoparticles improve the physicochemical properties and the hepatoprotective effects of naringenin in orally-administered rats with CCl(4)-induced acute liver failure. Pharm Res. 2009;26(4):893-902.

112. Hariharan S, Bhardwaj V, Bala I, Sitterberg J, Bakowsky U, Ravi Kumar MN. Design of estradiol loaded PLGA nanoparticulate formulations: a potential oral delivery system for hormone therapy. Pharm Res. 2006;23(1):184-95.

113. Vicentini FT, Simi TR, Del Ciampo JO, Wolga NO, Pitol DL, Iyomasa MM, Bentley MV, Fonseca MJ. Quercetin in W/o microemulsion: in vitro and in vivo skin penetration and efficacy against UVB-induced skin damages evaluated in vivo. Eur J Pharm Biopharm. 2008;69(3):948-57.

114. Priprem A, Watanatorn J, Sutthiparinyanont S, Phachonpai W, Muchimapura S. Anxiety and cognitive effects of quercetin liposomes in rats. Nanomed Nanotechnol Biol Med. 2008:4(1):70-8

115. Wu TH, Yen FL, Lin LT, Tsai TR, Lin CC, Cham TM. Preparation, physicochemical characterization, and antioxidant effects of quercetin nanoparticles. Int J Pharm. 2008;346(1-2):160-8.

116. Park JH, Gu L, von Maltzahn G, Ruoslahti E, Bhatia SN, Sailor MJ. Biodegradable luminescent porous silicon nanoparticles for in vivo applications. Nat Mater. 2009;8(4):331-6

117. Gou M, Men K, Shi H, Xiang M, Zhang J, Song J, Long J, Wan Y, Luo F, Zhao $X$, et al. Curcumin-loaded biodegradable polymeric micelles for colon cancer therapy in vitro and in vivo. Nanoscale. 2011;3(4):1558-67.

118. Long Q, Xiel Y, Huang Y, Wu Q, Zhang H, Xiong S, Liu Y, Chen L, Wei Y, Zhao $X$, et al. Induction of apoptosis and inhibition of angiogenesis by PEGylated liposomal quercetin in both cisplatin-sensitive and cisplatinresistant ovarian cancers. J Biomed Nanotechnol. 2013;9(6):965-75.
119. Cebecioglu R, Yildirim M, Akagunduz D, Korkmaz I, Tekin HO, Atasever-Arslan B, Catal T. Synergistic effects of quercetin and selenium on oxidative stress in endometrial adenocarcinoma cells. Bratisl Lek Listy. 2019;120(6):449-55

120. Sadhukhan P, Kundu M, Chatterjee S, Ghosh N, Manna P, Das J, Sil PC. Targeted delivery of quercetin via $\mathrm{pH}$-responsive zinc oxide nanoparticles for breast cancer therapy. Mater Sci Eng C. 2019;100:129-40.

121. Tao S-f, He H-f. Chen Q: Quercetin inhibits proliferation and invasion acts by up-regulating miR-146a in human breast cancer cells. Mol Cell Biochem. 2015;402(1-2):93-100.

122. Xavier CP, Lima CF, Rohde M, Pereira-Wilson C. Quercetin enhances 5-fluorouracil-induced apoptosis in MSI colorectal cancer cells through p53 modulation. Cancer Chemother Pharmacol. 2011;68(6):1449-57.

123. Atashpour S, Fouladdel S, Movahhed TK, Barzegar E, Ghahremani MH, Ostad SN, Azizi E. Quercetin induces cell cycle arrest and apoptosis in CD133+ cancer stem cells of human colorectal HT29 cancer cell line and enhances anticancer effects of doxorubicin. Iran J Basic Med Sci. 2015;18(7):635

124. Zhao J, Fang Z, Zha Z, Sun Q, Wang H, Sun M, Qiao B. Quercetin inhibits cell viability, migration and invasion by regulating miR-16/ HOXA10 axis in oral cancer. Eur J Pharmacol. 2019;847:11-8.

125. Ma YS, Yao CN, Liu HC, Yu FS, Lin JJ, Lu KW, Liao CL, Chueh FS, Chung JG. Quercetin induced apoptosis of human oral cancer SAS cells through mitochondria and endoplasmic reticulum mediated signaling pathways. Oncol Lett. 2018;15(6):9663-72.

126. Zhang W, Yin G, Dai J, Sun YU, Hoffman RM, Yang Z, Fan Y. Chemoprevention by quercetin of oral squamous cell carcinoma by suppression of the NF-kappaB signaling pathway in DMBA-treated hamsters. Anticancer Res. 2017;37(8):4041-9.

127. Kabirifar R, Ghoreshi Z-A-S, Safari F, Karimollah A, Moradi A, EskandariNasab E. Quercetin protects liver injury induced by bile duct ligation via attenuation of Rac1 and NADPH oxidase 1 expression in rats. Hepatobiliary Pancreat Dis Int. 2017;16(1):88-95.

128. Lu J, Wang Z, Li S, Xin Q, Yuan M, Li H, Song X, Gao H, Pervaiz N, Sun $X$. Quercetin Inhibits the Migration and Invasion of HCCLM3 Cells by Suppressing the Expression of p-Akt1, Matrix Metalloproteinase (MMP) MMP-2, and MMP-9. Med Sci Monit. 2018:24:2583.

129. Erdogan S, Turkekul K, Dibirdik I, Doganlar O, Doganlar ZB, Bilir A, Oktem G. Midkine downregulation increases the efficacy of quercetin on prostate cancer stem cell survival and migration through PI3K/AKT and MAPK/ERK pathway. Biomed Pharmacother. 2018;107:793-805.

130. Shu Y, Xie B, Liang Z, Chen J. Quercetin reverses the doxorubicin resistance of prostate cancer cells by downregulating the expression of c-met. Oncol Lett. 2018;15(2):2252-8.

131. Giuliani C. The flavonoid quercetin induces AP-1 activation in FRTL-5 thyroid cells. Antioxidants. 2019;8(5):112.

132. Calgarotto AK, Maso V, Junior GCF, Nowill AE, Latuf Filho P, Vassallo J, Saad STO. Antitumor activities of quercetin and green tea in xenografts of human leukemia HL60 cells. Sci Rep. 2018:8(1):3459.

133. Shen X, Si Y, Wang Z, Wang J, Guo Y, Zhang X. Quercetin inhibits the growth of human gastric cancer stem cells by inducing mitochondrialdependent apoptosis through the inhibition of PI3K/Akt signaling. Int J Mol Med. 2016;38(2):619-26.

134. Chang JH, Lai SL, Chen WS, Hung WY, Chow JM, Hsiao M, Lee WJ, Chien $\mathrm{MH}$. Quercetin suppresses the metastatic ability of lung cancer through inhibiting Snail-dependent Akt activation and Snailindependent ADAM9 expression pathways. Biochim Biophys Acta. 2017;1864(10):1746-58.

135. Zhang $P$, Zhang X. Stimulatory effects of curcumin and quercetin on posttranslational modifications of p53 during lung carcinogenesis. Hum Exp Toxicol. 2018;37(6):618-25.

136. Zhang S, Huang J, Xie X, He Y, Mo F, Luo Z. Quercetin from polygonum capitatum protects against gastric inflammation and apoptosis associated with Helicobacter pylori infection by affecting the levels of p38MAPK, BCL-2 and BAX. Molecules. 2017;22(5):744.

137. Nwaeburu CC, Bauer N, Zhao Z, Abukiwan A, Gladkich J, Benner A, Herr I. Up-regulation of microRNA let-7c by quercetin inhibits pancreatic cancer progression by activation of Numbl. Oncotarget. 2016:7(36):58367-80. 
138. Kim JH, Kim MJ, Choi KC, Son J. Quercetin sensitizes pancreatic cancer cells to TRAIL-induced apoptosis through JNK-mediated CFLIP turnover. Int J Biochem Cell Biol. 2016;78:327-34.

139. Sirotkin AV, Hrabovszká S, Štochmal'ová A, Grossmann R, Alwasel S, Halim Harrath A. Effect of quercetin on ovarian cells of pigs and cattle. Anim Reprod Sci. 2019;205:44-51.

140. Fatease AA, Shah V, Nguyen DX, Cote B, LeBlanc N, Rao DA, Alani AWG. Chemosensitization and mitigation of Adriamycin-induced cardiotoxicity using combinational polymeric micelles for co-delivery of quercetin/ resveratrol and resveratrol/curcumin in ovarian cancer. Nanom Nanotechnol Biol Med. 2019;19:39-48.
141. Kolesarova A, Roychoudhury S, Klinerova B, Packova D, Michalcova K, Halenar M, Kopcekova J, Mnahoncakova E, Galik B. Dietary bioflavonoid quercetin modulates porcine ovarian granulosa cell functions in vitro. J Environ Sci Health Part B. 2019;54:533-7.

\section{Publisher's Note}

Springer Nature remains neutral with regard to jurisdictional claims in published maps and institutional affiliations.
Ready to submit your research? Choose BMC and benefit from:

- fast, convenient online submission

- thorough peer review by experienced researchers in your field

- rapid publication on acceptance

- support for research data, including large and complex data types

- gold Open Access which fosters wider collaboration and increased citations

- maximum visibility for your research: over $100 \mathrm{M}$ website views per year

At BMC, research is always in progress.

Learn more biomedcentral.com/submissions 